\title{
An Assessment of Wind Power Generation Potential for Margate Town in South Africa
}

\author{
Chipo Shonhiwa*, Patrick Mukumba \\ Mathematics and Physics Department, Bindura University of Science Education, Bindura, Zimbabwe
}

Email address:

shonhiwachipo@gmail.com (C. Shonhiwa)

To cite this article:

Chipo Shonhiwa, Patrick Mukumba. An Assessment of Wind Power Generation Potential for Margate Town in South Africa. International Journal of Energy and Power Engineering. Vol. 4, No. 2, 2015, pp. 32-37. doi: 10.11648/j.ijepe.20150402.13

\begin{abstract}
Before setting up a wind farm at any given site, it is very important to evaluate its wind power potential to find its physical and economic sustainability. To date, there is limited research output on wind resource assessment for Margate town in South Africa and this might be one of the factors affecting the uptake of wind technologies in this area. This study aimed to assess the wind power potential of Margate. Three-year-long, hourly average wind speed series between January 2010 and December 2012 for Margate town were statistically analysed using the Weibull distribution function. The dimensionless Weibull shape parameter $(k)$ varied from 2.1 to 2.2 while the scale parameter $(c)$ ranged between 4.1 and $4.3 \mathrm{~ms}^{-1}$. The most probable wind speed $\left(v_{m p}\right)$ ranged from 3.0 to $3.2 \mathrm{~ms}^{-1}$. The wind power densities fluctuated from 57.8 to $64.0 \mathrm{Wm}^{-2}$.The average of the measured wind speeds $\left(v_{m}\right)$ for the whole period was less than $5 \mathrm{~ms}^{-1}$. Basing on the wind classification done by European Wind Energy Association (EWEA), Margate town is not favourable for the installation of wind turbines. However according to the rule of thumb for mean yearly wind speeds set by American Wind Energy Association (AWEA), the town is suitable for installation of stand-alone systems. It is thus recommended to small scale wind turbines for stand-alone applications such as supplying power to individual houses and irrigation in this town.
\end{abstract}

Keywords: Wind Speed, Weibull Distribution, Weibull Parameter, Wind Power Density

\section{Introduction}

Though there is no particular Millennium Development Goal (MDG) on energy, it was universally established that the provision of energy services is necessary to the achievement of MDGs at the World Summit for Sustainable Development [1]. The demand for modern energy services is on the increase and is projected to double the current levels by 2030 due to a steady economic growth and the rural electrification [2]. Hence the Department of Energy, with the cooperation of Eskom has been mandated to provide sustainable energy in order to achieve the MDGs.

About $95 \%$ of electricity in the country is produced by Eskom of which $90 \%$ comes from burning coal [3]. This makes South Africa the $14^{\text {th }}$ highest climate change contributor in the world [4] from anthropogenic emission of greenhouse gases and the top contributor in the Southern African Development Community (SADC) region [5]. With the Department of Energy's plans to build more coal power plants, pollution from energy production is expected to increase. Although the South African coal reserves are reasonably easier and cheaper to mine, they will be depleted in about 50 years if the current usage rate continues and no new deposits are discovered [2]. To this end the government is advocating for increased use of renewable energy sources since they play two crucial roles in sustainable development: (i) they can be used to replace diminishing carbon based fuels and (ii) they are cleaner sources of energy which will help in abating climate change [6].

In South Africa, wind has been given higher priority in electricity generation than the other renewable energy resources [7]. Between 2002 and 2005 Eskom ran a research and Demonstration Project north of Cape Town known as Klipheuwel Pilot Wind Farm, which was the first large wind turbine facility in sub-Saharan Africa [2]. In that period it produced about $12 \mathrm{GWh}$ of electricity and reduced carbon dioxide emissions by 11000 tonnes [2]. A National Demonstration Project comprising four 1.3 MW wind turbines was commissioned in 2008 at Darling Wind Farm in the Western Cape Province [2]. This was to be used as a case study for future public-private partnerships when using renewable energy resources for electricity generation. The construction of the first commercial wind farm at the Coega 
Industrial Development Zone in Port Elizabeth, in the Eastern Cape province was $60 \%$ complete by November 2013 [8].

Although currently the wind energy industry is the fastest growing sector of the international renewable energy industry $[9,10]$, the accomplishment of a constant cost decrease in the production of wind power is still the main hurdle. This is due to high capital requirement (cost of wind turbines, foundations and grid connection) and the electricity generation costs which depend on the size of the wind turbine, number of wind turbines and the mean wind speed at the specific location. [11]. Consequently investors are favouring large wind turbines, which result in lower initial and running expenditures per every kilowatt-hour produced [11].

Wind speed is the most significant factor influencing the production of wind power and impact on per kilowatt-hour electricity production cost. Since it varies in time: time of day and season; and in space: geographical location, height above ground and type of terrain, it determines the physical location of the wind farm and affects the quality and quantity of power produced. Thus wind resource assessment is a prerequisite to installing a wind turbine or wind farm. As a rule of thumb, yearly mean wind speeds of $5 \mathrm{~ms}^{-1}$ are required for grid-connected power generation while an average of $3 \mathrm{~ms}^{-1}$ to $4 \mathrm{~ms}^{-1}$ are required for off-grid and mechanical applications such as battery charging and water pumping [12]. Being a random parameter, wind speed characteristics can be obtained using different statistical methods to analyse measured wind speed data. These include lognormal function, logistical function, beta function, Gamma function, Rayleigh function and Weibull function. The Weibull distribution has been recommended for use by many authors since it fits a wide range of wind data when compared to other families of distribution [4] and this approach has been adopted in this paper. The Weibull distribution function has been used to assess the viability of large wind turbines in Margate in KwaZulu-Natal province of South Africa.

\section{Methodology}

\subsection{Site and Wind Speed Data}

Margate is a seaside resort town on the south coast of KwaZulu-Natal province. It is about $20 \mathrm{~km}$ southwest of port Shepstone. The geographical coordinates of the weather station are shown in Table 1. Being a coastal town it might have suitable sites for setting up wind farms.

The wind speed data used in this study in hourly time series format were measured from 2010 -2012 by South African Weather Services (SAWS) at a meteorological weather station in Margate.

Table 1. Geographical location on Margate.

\begin{tabular}{lllll}
\hline Location & Climate Number: & Latitude & Longitude & Height (m) \\
\hline Margate & $0182591 \mathrm{~A} 4$ & -30.8500 & 30.3330 & 154 \\
\hline
\end{tabular}

\subsection{The Weibull Distribution Function}

The Weibull distribution function is given by [13]:

$$
\mathrm{f}(v ; k, c)=\frac{k}{c}\left(\frac{v}{c}\right)^{k-1} \exp \left[-\left(\frac{v}{c}\right)^{k}\right] \quad \text { for } v>0 \text { and } k, c>0
$$

The function illustrates the number of hours per month or per year (fraction of time) during which a given wind speed, $v\left(\mathrm{~ms}^{-1}\right)$, can possibly prevail at a particular site. A frequency distribution curve is obtained if the fractional frequency distribution is plotted as a function wind speed. The most frequent wind speed corresponds to the maximum of this curve. The Weibull scale parameter $(c)$ shows how 'windy' the location is. It is concerned about the distribution of windy days.

The corresponding cumulative distribution, $F(v, k, c)$, is the integral of the probability density function and it is expressed as [13]:

$$
F(v ; k, c)=1-\exp \left[-\left(\frac{v}{c}\right)^{k}\right]
$$

Various methods have been suggested for the estimation of Weibull parameters $k$ and $c$. In this study, the mean wind speed - standard deviation is used [10,4];

$$
\begin{gathered}
k=\left(\frac{\sigma}{v_{m}}\right)^{-1.086} \quad 1 \leq k \leq 10 \\
c=\frac{v_{m} k^{2.6674}}{0.184+0.816 k^{2.73855}}
\end{gathered}
$$

where $\sigma$ is the standard deviation of the measured wind speed given by (5).

$$
\sigma=\left[\frac{1}{n-1} \sum_{i=1}^{n}\left(v_{i}-v_{m}\right)^{2}\right]^{\frac{1}{2}}
$$

and $v_{m}$ is the average of measured wind speeds defined mathematically as:

$$
v_{m}=\frac{1}{n} \sum_{i=1}^{n} v_{i}
$$

with $n$ being the number of data set and $v_{i}$ is the wind speed in time step $i$.

The standard deviation gives the measure of the amount of wind speeds' variation from the mean. A low standard deviation indicates that the wind speeds tend to be very close to the mean velocity and the chances of producing good quality power will be high since there will be no much variation in wind speeds.

\subsection{Wind Power Density}

Wind power density, $P_{d}$, is a function of the frequency 
distribution of the wind speed, air density, $\rho\left(\mathrm{kgm}^{-3}\right)$, and the mean value, $v$, of the third power of the wind speed. It is thus more reliable for the estimation of wind power potential for a specific site than wind speed [14]. For the Weibull distribution function $(f(v, c, k)$, it can be calculated by the following integration [13]:

$$
P_{d}=\frac{1}{2} \int_{0}^{\infty} \rho v^{-3} f(v ; k, c) d v
$$

Replacing $f(v, c, k$ in equation (7) by equation (1) gives [4]:

$$
P_{d}=\frac{1}{2} \rho c^{3} \Gamma\left(1+\frac{3}{k}\right)
$$

where $\Gamma$ is the gamma function given by (9).

$$
\Gamma(x)=\int_{0}^{\infty} t^{x-1} e^{-t} d t
$$

When the actual time-series data is available, wind power density is calculated by [13]:

$$
P_{d}=\frac{1}{2} \rho v^{-3}
$$

For the Rayleigh distribution, the wind power density is given as [10]:

$$
p_{d}=\frac{3}{\pi} \rho v_{m}^{3}
$$

\subsection{Most Probable Wind Speed}

The most probable wind speed $\left(v_{m p}\right)$ corresponds to the peak of the probability density function and represents the most likely wind speed to be experienced at a given site [4, $15,16]$. It is mathematically given by (12)

$$
v_{m p}=c\left(1-\frac{1}{k}\right)^{\frac{1}{k}}
$$

\subsection{Optimal Wind Speed}

The wind speed that produces the maximum amount of wind energy using a turbine, optimal wind speed $\left(v_{o p}\right)$ is calculated using $(13)[4,15]$.

$$
v_{o p}=c\left(1+\frac{2}{k}\right)^{\frac{1}{k}}
$$

\section{Results and Discussion}

\subsection{Margate Wind Speed Characteristics}

The daily mean wind speeds for Margate for the period 2010 to 2012 are shown in Figure 1. During this period, four days were calm: 5 October 20211; 27 May, 8 and 12 September 2012. The maximum daily average was attained on the $8^{\text {th }}$ of August 2012. Throughout the whole period, most days had average wind speeds less than $6 \mathrm{~ms}^{-1}$.

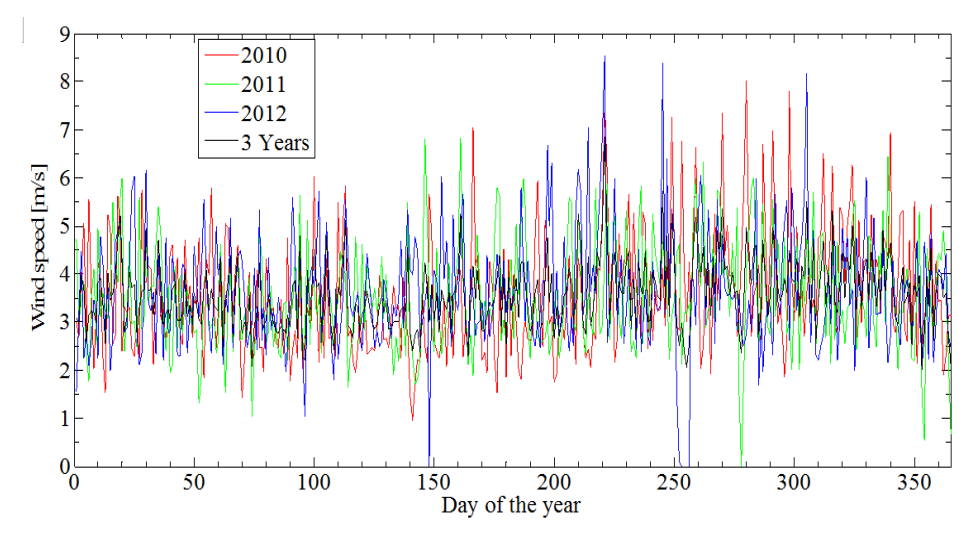

Figure 1. Daily mean wind speeds.

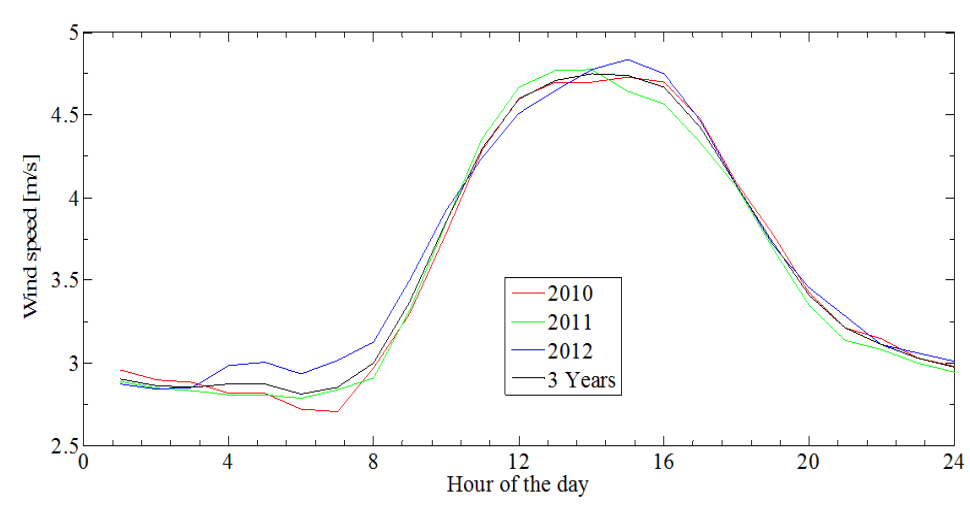

Figure 2. Diurnal wind speed variation for Margate between 2010 and 2012. 
The hourly mean wind speed variations are shown in Figure 2. The trend for the hourly mean wind speeds is the same for the three years and the values are almost the same for the corresponding hours. During the night it is relatively calm when compared with the day. The wind speed starts to increase from $2.8 \mathrm{~ms}^{-1}$ around 6:00 am to a peak of $4.7 \mathrm{~ms}^{-1}$ for 2010 and 2011 and $4.8 \mathrm{~ms}^{-1}$ for 2012 between 2:00 and 3:00 pm. The wind speed start to decrease thereafter.

The monthly mean wind speeds for Margate for the period 2010 - 2012 are shown in Figure 3. It is clear from the diagram that the mean monthly wind speed varies from 2.9 $\mathrm{ms}^{-1}$ in May 2010 to $4.5 \mathrm{~ms}^{-1}$ in September 2012. Generally the mean wind speeds are lower during the first half of the year than the last half for the three years. The yearly mean wind speeds are 3.8, 3.7 and $3.8 \mathrm{~ms}^{-1}$ for 2010, 2011 and 2012 respectively. Basing on the rule of thumb for mean yearly wind speeds [12], Margate is not suitable for large wind power plants for grid connection. However it is suitable for off-grid electrical generation and water pumping.

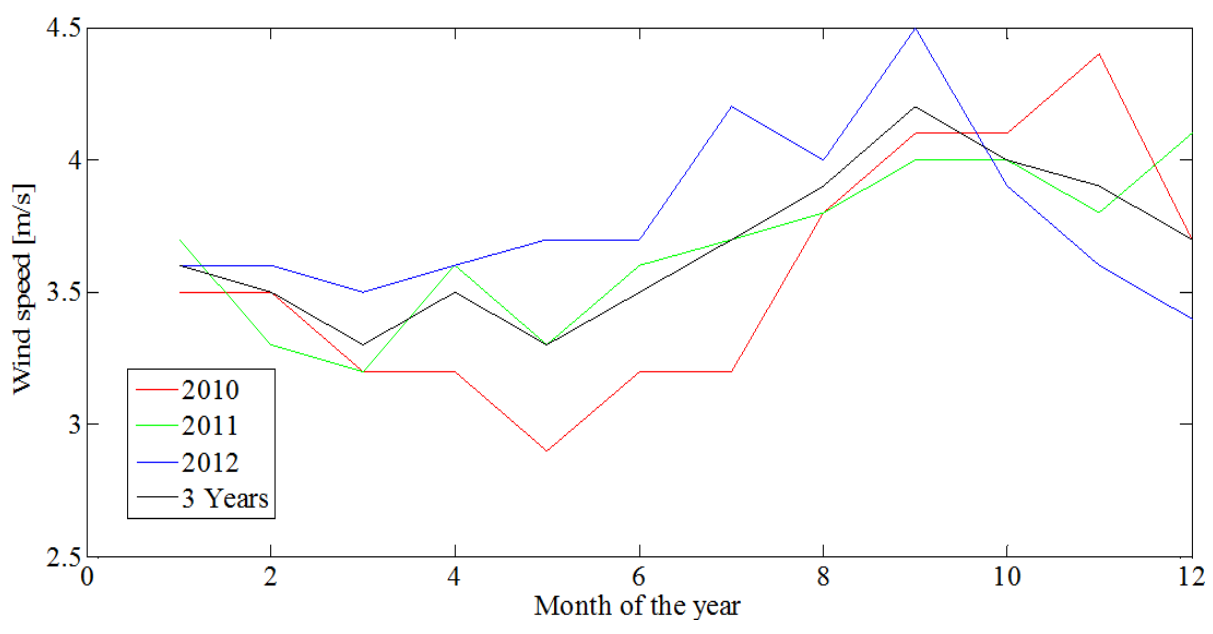

Figure 3. Mean monthly wind speeds.

\subsection{Margate Weibull Parameters}

The Weibull distribution function is shown in Figure 4. This distribution is not spread over a wider range and is skewed to lower wind speeds hence the probability of having high most probable wind speeds $\left(v_{m p}\right)$ are low. From the skewedness of the graph it is clear that the most probable wind speed for all the three years is less than $5 \mathrm{~ms}^{-1}$.

The cumulative distribution function is shown in Figure 5. The graph shows that the frequency of having wind speeds in the range $0 \mathrm{~ms}^{-1}$ to $5 \mathrm{~ms}^{-1}$ is 0.8 . This implies that the probability of having wind speeds higher than $5 \mathrm{~ms}^{-1}$ in Margate is only 0.2 .

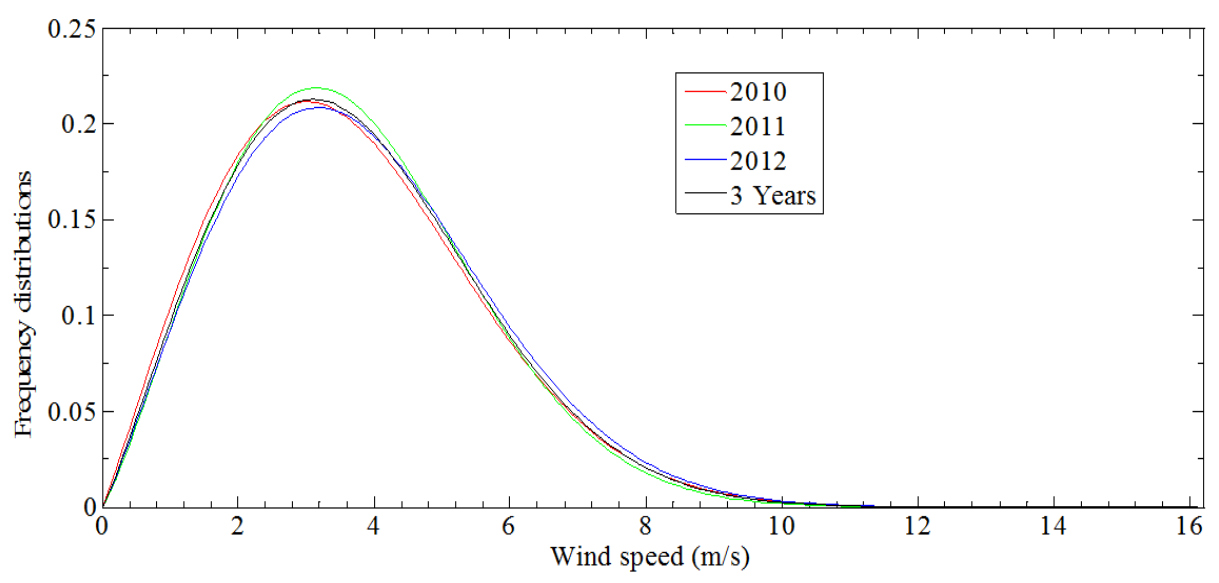

Figure 4. The annual Weibull probability density frequency for Margate for 2010 -2012.

From these results, the site is suitable for wind turbines that have cut-in wind speeds less than $5 \mathrm{~ms}^{-1}$ if they are to operate for the greater part of the period in a year. Basing on large wind turbines that are currently on the market that have high cut- in wind speeds [17], the site is not favourable for grid connected wind farms. 


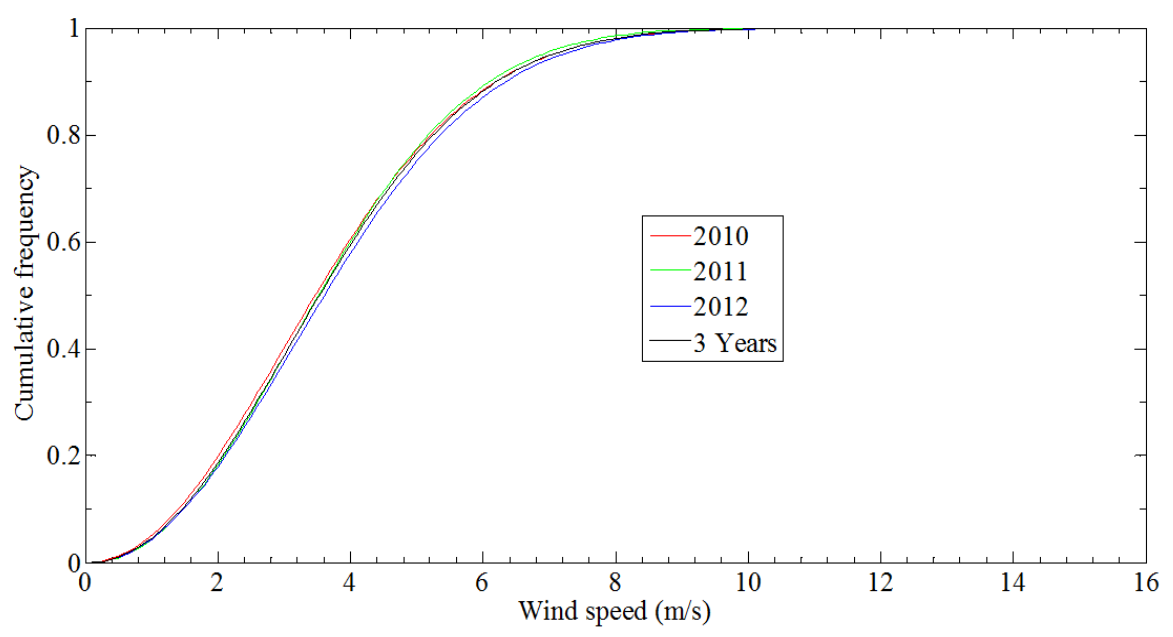

Figure 5. The annual Weibull cumulative frequency for Margate for 2010 - 2012.

The Weibull parameters, other wind characteristics and power density for the three year period being considered are presented in Table 2. The parameter $k$, which varies by 0.1 for the period has a smaller temporal variation than the parameter $c$ which varies from $4.1 \mathrm{~ms}-1$ to $4.3 \mathrm{~ms}-1$. The low values of $c$ are in agreement with low values of $v_{m}$ and the left skewedness of the annual Weibull probability density frequency.

Table 2. Yearly Weibull parameters and characteristic speeds for Margate for 2010 -2012.

\begin{tabular}{|c|c|c|c|c|c|c|}
\hline \multirow[b]{2}{*}{ Year } & \multicolumn{6}{|l|}{ Parameter } \\
\hline & $v_{m}\left(\mathrm{~ms}^{-1}\right)$ & $c\left(\mathrm{~ms}^{-1}\right)$ & $k$ & $P_{d}\left(\mathrm{Wm}^{-2}\right)$ & $v_{o p}\left(\mathrm{~ms}^{-1}\right)$ & $v_{m p}\left(\mathrm{~ms}^{-1}\right)$ \\
\hline 2010 & 3.8 & 4.1 & 2.1 & 57.8 & 5.8 & 3.0 \\
\hline 2012 & 3.8 & 4.3 & 2.1 & 64.0 & 5.9 & 3.2 \\
\hline 3 Yrs & 3.8 & 4.2 & 2.1 & 60.1 & 5.7 & 3.1 \\
\hline
\end{tabular}

\subsection{Wind Power Density}

The wind power densities for the weather station are 57.8 , 58.7, 64.0 and $60.1 \mathrm{Wm}^{-2}$ for 2010, 2011, 2012 and the whole three year period respectively. According to classification done by European Wind Energy Association (EWEA), the wind characteristics and categories are indicated as below [15]:

$$
\begin{aligned}
& \text { fairly good }\left(6.5 \mathrm{~ms}^{-1}, \approx 300-400 \mathrm{Wm}^{-2}\right) ; \\
& \operatorname{goog}\left(7.5 \mathrm{~ms}^{-1}, \approx 500-600 \mathrm{Wm}^{-2}\right) ; \\
& \text { very good }\left(8.5 \mathrm{~ms}^{-1}, \approx 700-800 \mathrm{Wm}^{-2}\right)
\end{aligned}
$$

Basing on this EWEA classification the Margate is not a favourable location for large wind turbine installation.

\section{Conclusion}

The most vital conclusions of the study are summarised below:

1. The low values of the Weibull shape parameter, k, indicate that there is greater variability of the hourly mean of the wind speed about the yearly mean wind speed. This may result in poor quality power being produced by the wind turbines since the quality of the power and energy delivery of a wind farm is determined to a large extent by the length of time during which the output remains constant. This output is largely dependent on wind speed, which is highly variable in this case.

2. The probability of having wind speeds higher than $5 \mathrm{~ms}^{-}$ ${ }^{1}$ in Margate is only 0.2 . Thus the site is suitable for wind turbines that have cut-in wind speeds less than 5 $\mathrm{ms}^{-1}$ if they are to operate for the greater part of the period in a year. As a result Margate is not suitable for installation of large wind turbines that have high cut-in wind speeds.

3. The wind power densities for the weather station are less than $100 \mathrm{Wm}^{-2}$ for the studied period. The mean monthly wind speeds are less than $5 \mathrm{~ms}^{-1}$ throughout the three years. Thus basing on the rule of thumb for mean yearly wind speeds set by AWEA and EWEA classification of wind characteristics and categories, Margate is not a favourable site for large wind power plants for grid connection. However it is suitable for offgrid electrical generation and water pumping.

Therefore it is recommended to install small wind turbines for off-grid applications in Margate.

\section{Acknowledgements}

I would like to thank the Bindura University of Science Education Capacity Building Department for offering me study leave to pursue $\mathrm{PhD}$ studies. 


\section{References}

[1] United Nations Development Programme. Energy for sustainable development, New York; 2004.

[2] Energy. In: Van Niekerk L. South Africa Yearbook 2012/2013. 20th Ed. Pretoria: Government Communication and Information System (GCIS); 2013.

[3] Department of Energy. 2014. Basic electricity overview. Accessed 20 July $2014 . \quad$ Available: http://www.energy.gov.za/files/electricity_frame.html.

[4] Ayodele TR, Jimoh AA, Munda JL, Agee JT. Statistical analysis of wind speed and wind power potential of Port Elizabeth using Weibull parameters. JESA 2012;23:30.

[5] Oxfam International. Climate change, development and energy problems in South Africa: Another world is possible. Monograph on the Internet: Earthlife Africa; 2009. Accessed 20 July 2014. Available: http://www.oxfam.org/sites/www.oxfam.org/files/oi_climate_c hange_south_africa.pdf

[6] Marques AC, Fuinhas JA. Drivers promoting renewable energy: A dynamic panel approach. Renew Sust Energ Rev 2011;15: 1601-1608.

[7] Department of Minerals and Energy. Integrated resource plan for electricity 2010-2030. Final report; 2011, P. 73.

[8] Kolver L. Coega wind turbine manufacturing facility $60 \%$ complete. Engineering news; 2013. Accessed 24 July 2014. Available: http://www.engineeringnews.co.za/article/coegawind-turbine-manufacturing-facility-60-complete-2013-11-11
[9] Nor KM, Shaaban M, Rahman HA. Feasibility assessment of wind energy resources in malaysia based on NWP models. Renew Energ 2014;62:147.

[10] Adaramola MS, Agelin-Chaab M, Paul SS. Assessment of wind power generation along the coast of Ghana. Energ Convers Manage 2014; 77 61-69.

[11] Tong W. Fundamentals of Wind Energy. In: Tong W, EDITOR. Wind power generation and wind turbine design. Southampton: wit press; 2010.

[12] American Wind Energy Association. Basic principles of wind resource evaluation. 1998. Accessed 01 July 2014. Available: http://archive.today/tATuf\#selection-333.0-198.2

[13] Chang TP. Estimation of wind energy potential using different probability density functions. Appl Energ 2011;88: 1848-56.

[14] Mostafaeipour A, Sedaghat A, Dehghan-Niri AA, Kalantar V. Wind energy feasibility study for city of Shahrbabak in Iran. Renew Sust Energ Rev 2011;15: 2545- 56.

[15] Akpinar EK, Akpinar S. A statistical analysis of wind speed data used in installation of wind energy conversion systems. Energ Convers Manage 2005;46: 515-532.

[16] Nigim KA, Parker P. Heuristic and probabilistic wind power availability estimation procedures: improved tools for technology and site selection. Renew Energ 2007;32: 638-648.

[17] Shikha S, Bhatti TS, Kothari DP. Air concentrating nozzles: a promising option for wind turbines. INT J Energy Technology and Policy 2005;3: 394-412. 